\title{
LA COMISIÓN COROGRÁFICA: UN ATLAS DE LA INEQUIDAD
}

\section{THE COROGRAPHICAL COMMISSION: AN ATLAS OF INIQUITY}

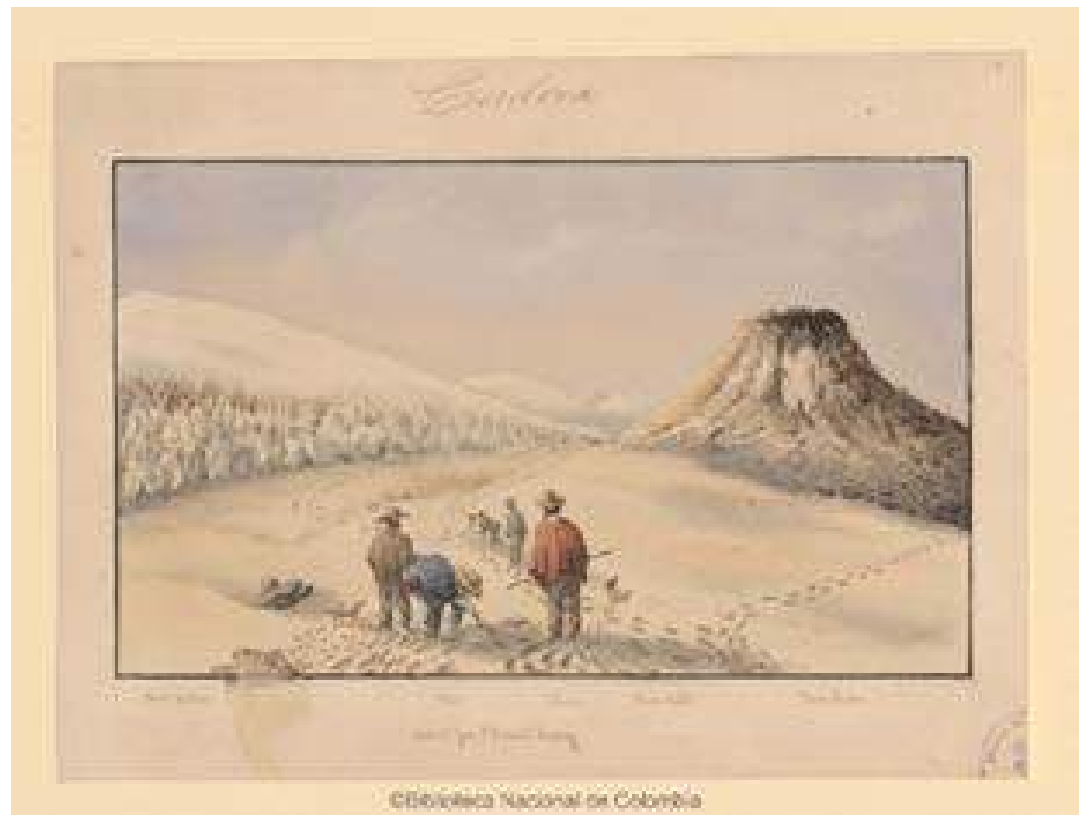

Figure 1 Mesa de Herve, Ruíz, Tolima, Santa Isabel y gran cráter: provincia de Córdoba / Enrique Price. Extraída de https://catalogoenlinea.bibliotecanacional.gov.co

\section{Jenny Carolina Álvarez Correa ${ }^{1}$}

Universidad Pedagógica y Tecnológica de

\section{Colombia}

1

Filiación institucional: Universidad Pedagógica y Tecnológica de Colombia

Enlace de registro en ORCID: https://orcid.org/0000-00031671-2400

Enlace de registro en Google académico: https://scholar. google.es/citations?user=EROek7lAAAAJ\&hl=es

Jenny Álvarez: jecaalco35@yahoo.es

\section{RESUMEN}

El propósito de este artículo es dar a conocer el análisis de la sociedad neogranadina del siglo XIX en cuanto a las diferencias y características que determina a dichas sociedades, 
que comúnmente se pueden ver como opuestas: pobres- ricos, urbanos- rurales, costa- altiplano y la manera en que la Comisión las percibió, las catalogó y los clasificó. Se acude a la mirada de los extranjeros y el interés que ellos tenían por conocer una nación joven, disímil con una rica diversidad racial, cuya unión dio como resultado una sociedad multicultural y mestiza, con grandes recursos naturales y con esperanza de progreso, siempre y cuando se establecieran medidas que permitieran obtener una sociedad prospera y civilizar a aquellos que consideraban "incivilizados".

PALABRAS CLAVE: Nueva Granada, Comisión Corográfica, clases sociales, vestido, nación, imagen.

\section{ABSTRACT}

The purpose of this article is to present the analysis of the nineteenth-century neogranadian society in terms of the differences and characteristics that determines such societies that can commonly be seen as opposite: poorrich, urban-rural, coast- plateau and the way the Commission perceived them, cataloged them and classified them. The attention of foreigners and the interest they had in knowing a young nation, dissimilar with a rich racial diversity whose union, resulted in a multicultural and mestizo society, with great natural resources and with hope of progress, provided when measures were established to obtain a prosperous society and civilize those who considered "uncivilized".

KEYWORDS: New Granada, Corographic Commission, social classes, dress, nation, image.

\section{INTRODUCCION}

La indumentaria como referente social ha sido un elemento importante dentro del estudio sobre la diferencia que existe dentro de los diferentes núcleos poblacionales. Los más pequeños detalles son los causantes de grandes transformaciones que al final se convierten en los más significativos para la satisfacción humana.

Cada lugar, cada espacio, cada circunstancia, cada evento, cada raza, cada prenda, fundamenta la realidad mediata de una nación junto con sus pobladores, de manera contundente. La historia de la identidad nacional, que se constituyó paso a paso, se da gracias a las grandes como a las pequeñas diferencias que hay entre cada uno de los habitantes del territorio colombiano.

En una sociedad republicana como lo fue la de mediados del siglo XIX, la vestimenta jugo un papel importante dentro de los distintos sectores sociales, como instrumento de diferenciación social, esta diferenciación la podemos observar a través de las producciones realizadas en el proyecto llevado a cabo por la Comisión Corográfica, el cual buscaba una imagen nacional.

Bajo esta mirada se llevó a cabo la idea de conocer más acerca de la importancia que tiene el vestido para el reconocimiento de determinada sociedad y como identificador y diferenciador entre clases sociales que emergen y se relacionan dentro de un mismo lugar.

\section{POBRES Y RICOS VISTEN DIFERENTE, POR LO TANTO, SON DIFERENTES}

Durante toda la historia de la humanidad, se ha visto las grandes diferencias de clases sociales y la división ideológica que hay entre las unas y las otras, la pobreza durante el siglo XIX se encontraba en amplios sectores de la sociedad neogranadina de este siglo, la cual 
estaba marcada por desigualdad y exclusión social y económica que dejo la época colonial, a las elites criollas y a los grupos plebeyos conformados por mestizos, mulatos, indígenas y negros esclavos. Los factores socioeconómicos que afectaron a esta sociedad se evidenciaron en la estructuración y formación de la nación, en el incremento de la ciudadanía a los sectores populares y en la participación del estado sobre asuntos que inicialmente estaban a cargo de la iglesia católica.

Las agitaciones sociales en los diferentes sectores contribuyeron a una diferenciación importante entre sus pobladores y en la vida material que se encontraba en los disímiles espacios, cuyas características principales permitieron conocer las circunstancias económicas de dicha sociedad; la clase de alimentación, el acceso a cierta clase de sitios, los trajes portados, los oficios realizados, las tradiciones heredadas, la educación, la raza, fueron los detalles que establecieron las clase sociales de la época, y fundamento la identidad de cada uno de los grupos que conformaron la nación.

En el texto de Martínez (1996), vestirse a la española, así fuera con paños tejidos en Quito, daba prestancia y era un anhelo de indígenas, mestizos y criollos; los esclavos, cuyo vestuario, controlado por las leyes de Indias y por los amos se reducía a los géneros más baratos -listado, gante, crudo, cotón y cholete cuando podían escapar a la vigilancia oficial se convertían en grandes consumidores de géneros de lujo.(...) La saya, el vestido de mayor gala, era de raso o seda y, si muy rica, de terciopelo o brocado, y se consideraba "peculiar de las señoras" como consta en quejas presentadas en Valledupar en 1807, por doña Concepción Loperena de Castro contra dos pardas libres, de profesión costureras, que dieron en ir a la iglesia con saya, mantón y abanico.

La colonia fue una época que marcó la historia nacional, contribuyo con los cambios y adecuaciones en la indumentaria de los miembros de los sistemas sociales, como paso con las instituciones militares a las cuales se le impuso el uso de un calzón ajustado bajo la rodilla, media punto y sombrero de tres picos.

Al final de este periodo e inicio de la república los viajeros extranjeros como Isaac Holton, hacen alusión a la pobre indumentaria de dichos militares y la ausencia de calzado en sus tropas, de igual manera se refiere al vestido anticuado de las mujeres neogranadinas, cuyas críticas contribuyeron a los cambios en la indumentaria y a la adquisición de nuevos estilos en la misma.

Martínez (1996) se refiere a los miembros de la clase alta como aquellos quienes lideraron estos cambios, los cuales se manifestaron en los uniformes de los colegios, la adopción de sombreros femeninos el uso de corsés, criolinas y quitrines, que modificarían la imagen, la silueta y hasta la anatomía de las damas. También surgió un desapego a rasgos del vestuario local, que, como la ruana y la mantilla, identificaban a una cultura eminentemente mestiza.

La sociedad neogranadina después de las guerras de independencia, queda fracturada y con muchos despojos humanos a causa de la pobreza que esta ocasionó. Tanto ricos como pobres sufren por las falencias y rezagos que conllevaron a las nuevas adaptaciones para suplir sus necesidades; los ricos ocultan sus carencias bajo las grandes prendas de su indumentaria, en el caso de los hombres bajo el redingote y los pobres sobrellevan su pobreza con los viejos elementos que poseen y que los adecúan para seguir dándole su respectivo uso, parte de esta rutina se basó en la adecuación de las prendas de vestir por medio de su cuidado a través del arreglo de las prendas por medio del remiendo.

Dentro de las poblaciones pequeñas y aisladas se mantuvo vigente el uso del vestido 
femenino de la independencia con algunas características de esta época y con combinaciones de las formas del vestido español de los anteriores siglos, como lo señala Forero Reyes (1989): "anchísimas enaguas de bayeta de Castilla y mantellina de la misma tela; ropa interior de lienzo ordinario (llamado "de la tierra"); camisa de blanco lienzo con arandelas de Bretaña, bordadas de ojalillos o de hilos, lanillas y sedas de colores, de manga muy corta y grande escote, que las damas cubrían con el indispensable pañuelo "rabo de gallo", de ancha cenefa floreada y vivos colorines, o de lanilla o seda; finas alpargatas de capellada labrada, sujetas a los pies con hiladillos de hilo de Castilla; sombreros de alta copa y medianas alas con cinta negra; zarcillos, gargantillas de meloncillos de oro, anillos de plata $\mathrm{u}$ oro, e indispensablemente, devoto rosario de coquito, con extremo, cruz, pasadoras y cucharilla para los oídos, de oro".

El anterior traje se consideró un traje típico y luego fue considerado como el traje nacional.

Mientras las clases altas de mediados de siglo ajustaron su indumentaria a la moda internacional, las clases bajas ajustaban el vestuario a los que la producción artesanal nacional hacía, como los lienzos de algodón provenientes del Socorro.

Para Martínez (1996) el paso definitivo hacia la moda internacional se dio en la segunda mitad del siglo XIX, cuando los ricos empezaron a encargar sus ajuares desde Paris y a competir en elegancia y estilo.

El comercio fue una actividad muy importante en cuanto al abastecimiento de diferentes productos en la Nueva Granada colonial, al igual que en todos los sectores en el comercio se establecieron ciertas jerarquías según el rol que cada uno desempeñaba; se encontraban los comerciantes de alto rango, seguido de los mercaderes más pequeños y con menores in- gresos, los tratantes y los dueños de pequeños establecimientos de intercambio comercial entre poblaciones y al interior de las mismas ciudades y los asentamientos mineros.

La riqueza y la jerarquía social de los comerciantes más importantes al interior de la Nueva Granada implicaba, por supuesto, que eran hombres conservadores tanto política como socialmente, ya que tenían un fuerte vínculo con España y una profunda lealtad con su monarquía. (...) Después de la Independencia, los comerciantes tuvieron siempre buena representación en el Congreso Nacional y en los gobiernos provinciales, y el progreso político se identificaba fuertemente con el desarrollo del comercio nacional.

En efecto, como lo analiza Castro Carvajal (1996), la clase alta criolla de la capital, adoptó rápidamente los valores de la sociedad burguesa, en la que el dinero era medida importantísima de la posición social y una búsqueda individualista de progreso económico era admirada y emulada. Según las elites criollas liberales, el progreso social y económico de la nación neogranadina se basaba en el crecimiento y fortalecimiento comercial.

Ancízar (1854) en el recorrido que hace por San José de Cúcuta, logra recopilar cierta información sobre el valor de la aduana recaudada y la movilidad comercial que allí se da y lo recopila dentro de uno de sus informes el cual lo da a conocer a través de su libro "Peregrinación de Alpha".

"Sabiendo lo que son y serán las aduanas, a pesar de la severidad de los empleados y la vigilancia de los guardas, recogí cuidadosamente en cada cantón, y auxiliado por los vecinos más veraces y notables, los siguientes datos: 
Hay en el cantón San José 4.000 proletarios jornaleros, que unos con otros gastan $\$ 10$ en ropas extranjeras;

Son reales. 320.000

2.000 indios con medianas comodidades, que gastan $\$ 40$ 640.000

700 ricos, que gastan a $\$$ $1.120,000$

Hay en el cantón Rosario 2,000 jornaleros, que gastan a $\$ 8$. 128,000

450 individuos con mediana comodidades, que gastan a $\$ 25$ 90.000

150 ricos, que gastan a $\$ 100$ 120.000

Hay en el cantón Salazar o 5,500 jornaleros, que gastan a $\$ 4$. $.176,000$

2.000 individuos con medianas comodidades, que gastan a $\$ 10$. 160.000

500 ricos, que gastan a $\$ 100$. .$\underline{400.000}$

Suma el consumo anual de ropas extranjeras, rs. $3.154,000$

En cuyos cálculos se ha evitado toda exageración, como se conocerá comparando la masa de riquezas circulantes en la provincia con su población total. Risible cosa serían las aduanas si no fueran destructoras de la prosperidad pública, en cuanto se oponen a la extensión natural de los cambios, de la producción nacional y de los consumos baratos. Tengo la esperanza de verlas tan desacreditadas también como instrumentos fiscales, que al fin se persuadan nuestros estadistas de la conveniencia de abolirlas, sustituyendo algo más honroso para ellos y benéfico para el país.

Dentro de la sociedad neogranadina, la apariencia física era muy importante y se demostraba por medio del porte de cada uno de los elementos que conforman la indumentaria pues, según como se veían, eran tratados. Por eso fue fundamental y crucial para muchos la imagen y los pequeños detalles que influían para un el posicionamiento dentro un sector social.

De un artículo publicado en 1848 sobre la influencia del vestido, Martínez (1996) toma los siguientes apartes: "el traje del hombre ejerce una poderosa fuerza moral sobre su conducta. Si una persona decente se ve con zapatos flojos y sucios, la casaca empolvada, el cabello descompuesto, la corbata mal envuelta, deberá posiblemente sentir en sí propia una disposición de ánimo que corresponde a la negligencia del traje...si hubiera celo en los maestros y gobernantes... insensiblemente dejaríamos la inerte fisionomía indígena que nos caracteriza para tomar otra más animada y más suave y nuestros modales y nuestro traje adaptados al grado de cultura del sitio en que vivimos nos ahorrarían las sátiras y el ridículo que descargan sobre nosotros los extranjeros que vienen a visitarnos."

La imagen internacional que se proyectó de la nación en muchas ocasiones fue en contra de la que los gobiernos quisieron mostrar, pues en la Nueva Granada primaban los sectores populares más que las elites y los notables. En la práctica, y como lo describen repetidamente los viajeros europeos, como Holton y Hettner, la indumentaria de las gentes de la nueva república estaba condicionada por prejuicios raciales y diferencias sociales.

Ancízar (1854) da a conocer algunas descripciones de la indumentaria utilizada por la clase popular neogranadina, entre ella los "pobres": "En el distrito de Panipauna, pueblo minero, las mujeres visten unas enaguas de lienzo atadas al pescuezo, sacando los brazos por las aberturas laterales; los hombres llevan calzón ancho, y cuando salen por acá se ponen camisa. En Tunja las mujeres pobres visten saya y mantellina de bayeta oscura, llevan sombrero y andan embozadas, lo que las da el aire de frailes franciscanos: los artesanos y jornaleros abandonan las pesadas ruanas que les embarazan los movimientos, ni han dejado aquel exterior 
abatido que en los tiempos coloniales revelaba el menosprecio en que eran tenidos. En compensación las gentes acomodadas demuestran gusto y aseo en el vestido y las habitaciones, particularmente las damas, que son bellas, agraciadas y de una elegancia señoril sin afectación ni quijotería, candorosas y en extremo sensibles para las afecciones domésticas."

Las diferencias que se encuentran entre las clases sociales a parte del vestido se vieron reflejadas en los diferentes espacios como los monasterios y sitios de residencias. En cuanto a los monasterios eran utilizadas las indígenas y las esclavas para servir a las religiosas y a las mujeres que eran llevadas a dichos lugares.

Las edificaciones utilizadas por los pobladores neogranadinos también formaron parte de la diferenciación social en donde al igual que el vestido también fue dado a conocer por medio de los análisis iconográficos realizados por la Comisión Corográfica.

Como lo señala Rodríguez Jiménez (1996), la casa de alto y bajo, como se llamaba a la de dos pisos, era propia de las familias más ricas. Se requería gran para construir una edificación de esta complejidad. La teja y el adobe empezaron a ser utilizados en el siglo XVII, sin embargo, no todas las poblaciones contaban con fábricas para su producción, ni se los conseguía a lo largo del año. El precio de la teja hacía de distintivo de las casas que lo ensenaban en sus techos. La construcción de una vivienda de dos pisos llevaba varios años. Hoy los restauradores de estas viviendas encuentran que muchas se construyeron en forma interrumpida. (...) Una forma más modesta de casa de una planta, difundida en todas las ciudades neogranadinas, fue la construida en forma de $L$ alrededor de un patio central. (...) En estas casas vivía la gente de condición social media de las ciudades: blancos pobres y mestizos de algún patrimonio. (...) El bohío, o rancho de paredes de bahareque y techo de paja, era la vivienda común de la gente pobre de todas las ciudades coloniales. Estaba conformada por una sola alcoba que servía de dormitorio y sala. En la parte posterior una hornaza bajo una enramada de techo pajizo sin paredes era toda la cocina. En cada lugar, estas indicaban que allí vivían indígenas, mulatos y negros.

Las pinturas realizadas por la Comisión Corográfica evidencian las grandes diferencias entre estas dos clases sociales, muestran los contrastes que existen entre ellas y los diferentes ambientes sociales del cual hacen parte. Los "notables son dibujados en interiores y previamente adecuados y vestuario acorde con la ocasión para plasmarlos en las acuarelas, sin perder su posición, postura, su altives, elegancia y porte, no se muestran en ambientes familiares sino sociales. Mientras tanto los "pobres" se dibujan en sus ambientes populares, mostrando sus carencias y falencias, en actividades cotidianas de forma muy casual, sin ocultar sus atuendos o tal vez lo que quedan de ellos. En cuanto a la riqueza que ofrecen las láminas, se ven reflejadas en la pintura de las clases populares, pues dan más información sobre el real estilo de vida que llevan estos habitantes.

La ambigüedad en las acuarelas crea una especial importancia desde el punto de vista histórico-social puesto que permite el reconocimiento de la nación de una manera individual por parte de quien las observa, y permite analizarlas desde un punto de vista crítico por sus tintes raciales que en ellas se observa, de una $u$ otra manera clasista y de cierta forma no objetiva, puesto que obedecen al punto de vista de un grupo de intelectuales liberales de dicho siglo.

\section{REFLEXIÓN FINAL}

La sociedad colombiana a lo largo de su historia ha llevado a cabo diferentes procesos sociales, políticos, económicos y culturales que sentaron las bases para lograr adquirir una identidad propia. 
Tras la disolución española, surgen importantes procesos económicos y políticos que llegan con la independencia y exigen cambios cruciales dentro de la sociedad neogranadina, sin embargo dicha sociedad sigue movilizándose dentro de las herencias de sus colonizadores, por tanto surge la necesidad de conocer al país en todas sus dimensiones, bajo la idea de un imaginario nacional, dicha idea es llevada a cabo por intelectuales de la elite del momento quienes ponen en marcha el proyecto científico más importante en la historia nacional.

El proyecto realizado por la Comisión Corográfica bajo la dirección de Agustín Codazzi, fundamentó las bases para el conocimiento y reconocimiento integral del territorio, cuyo propósito principal fue el de construir la nación con características homogéneas. Dicha idea no se logró llevar a cabo de esa manera ya que Colombia se constituía por múltiples culturas y razas que lo hacía un país totalmente heterogéneo.

La importancia y reconocimiento que alcanzó la Comisión Corográfica se debió gracias a lo complejo y completo trabajo realizado bajo la mirada geográfica, cartográfica, social, cultural y política con que se llevó a cabo.

Los resultados obtenidos del recorrido realizado por las diferentes regiones de la Nueva Granada se convirtieron en una herramienta pedagógica, la cual dio a conocer la diversidad poblacional y la riqueza cultural de la nación, estableciéndola como un país de regiones.

La estructura de la estratificación social, continuó con la misma establecida por los españoles, pero con diferentes protagonistas, la idea liberal, de hacer una nación igualitaria nunca se llevó a cabo ya que dentro de la movilidad política no cabía la posibilidad de aceptar en el poder a individuos no pertenecientes a su nivel intelectual y económico o que hicieran parte de su círculo social gente de diferente estirpe.
La indumentaria se consideró como un fuerte referente social, puesto que clasificó a los habitantes neogranadinos, según su nivel de desarrollo, actividades económicas, actividades culturales, ubicación geográfica, posición social, raza, edad, estableciéndose como un símbolo cultural que se materializó por medio de la imagen.

\section{REFERENCIAS BIBLIOGRAFICAS}

MARTÍNEZ CARREÑO, Aída. La prisión del vestido. Aspectos sociales del traje en América Latina. Bogotá: Editorial Planeta, 1995.

MARTíNEZ CARREÑO, Aída. Un siglo de moda en Colombia. 1830-1930. Bogotá: Fondo Cultural Cafetero, 1981.

HOLTON, Isaac Farewell. La Nueva Granada: veinte meses en los Andes. Publicado en inglés: New York: Harper and Brothers, 1857. Traducción Ángela de López: Bogotá: Ediciones del Banco de la República, 1981.

CASTRO CARBAJAL, Beatriz. Historia de la vida cotidiana en Colombia. Bogotá: Editorial Norma, 1996.

RESTREPO, Olga, "Un imaginario de la nación. Lectura de láminas y descripciones de la Comisión Corográfica". Anuario Colombiano de Historia Social y de la Cultura, $N^{\circ} .26$ (1999): pp. 31-58.

APPELBAUM, Nancy P. Dibujar la nación. La Comisión Corográfica en la Colombia del siglo XIX. Bogotá: Universidad de los Andes, ediciones uniandes, fondo de cultura económica, 2017.

ANCÍZAR, Manuel (1853): La peregrinación de Alpha por las provincias del norte de La Nueva Granada en 1850-1851, Bogotá, Echeverría. Versión en línea, Banco de la República, Biblioteca Luis Ángel Arango, Biblioteca virtual:

http://www.lablaa.org/blaavirtual/historia/perealpha/indice.htm. 